Article

\title{
Shared Short-Term Rentals for Sustainable Tourism in the Social-Network Age: The Impact of Online Reviews on Users' Purchase Decisions
}

\author{
Jie Zhao* $*$ and Zhixiang Peng \\ School of Business, Anhui University, Hefei 230601, China \\ * Correspondence: zhaojie@ahu.edu.cn
}

Received: 9 July 2019; Accepted: 26 July 2019; Published: 28 July 2019

\begin{abstract}
With the development of social networks and the Internet-based sharing economy, shared short-term rentals are emerging as a new kind of service that provides a convenient way for people to buy short-term rental services in cities through social-network-enabled platforms. However, like other social-network-based services, shared short-term rental is also likely to be impacted by online reviews. This paper aims to investigate the impact of online reviews on users' purchase decisions toward shared short-term rentals, and further to provide optimization suggestions for the future advance of shared short-term rentals. The contributions of this paper are many-fold. First, we introduce the Stimuli-Organism-Response (SOR) model into the study and propose new variables for the model, including stimulus variables, organism variables, response variable, and moderating variables. Second, we propose eight hypotheses to evaluate the impact of online reviews on users' purchase decisions toward shared short-term rentals. Finally, we collect data through a questionnaire survey and present comprehensive results on many aspects. Based on the data analysis, we find out that the quality of online reviews impacts users' perceived value and perceived risk, which in turn impacts users' purchase decisions toward shared short-term rentals. In addition, the cognitive needs of users can adjust the impact of online reviews on the perceived risk of users but have no explicit adjusting effect for users' perceived value. Further, we present some research implications as well as suggestions for rental platforms to advance shared short-term rentals in the Internet age.
\end{abstract}

Keywords: shared short-term rental; sustainable tourism; online reviews; purchase decisions; social networks

\section{Introduction}

The popularity of the Internet and social networks have made the sharing economy develop rapidly in modern city life [1]. Internet-based sharing economy, such as shared rentals, shared cars, and shared bicycles, offers many kinds of smart services to cities, becoming an intrinsic feature of smart cities [2,3]. Among all sharing economy products, shared short-term rentals have become a recent focus, because of the rapid development of the sustainable-tourism industry [4,5]. An Internet-based platform for shared short-term rentals provides a convenient way for people to sell or buy short-term rental services in cities through the Internet. This is especially helpful for tourists. As a result, many people consider shared short-term rentals as their first choice of accommodation during a travel.

Shared short-term rental is a product of sharing economy in the field of hotel accommodation [6]. It means that the owners of houses can share their rooms or houses to get economic returns within a certain time period. This new type of leasing mode develops rapidly due to its diversified leasing style, simple operation, and low cost. However, due to the inequality of information, consumers usually do not trust shared rentals and are eager to know necessary information about shared rentals before they 
buy the service [7]. Therefore, online reviews, probably provided by social-network-enabled rentals platforms, become a major information source for people to make decisions [8]. Online reviews are popular in social networks; they can reflect the real experiences of consumers, which are more reliable than the advertisements or other information offered by service providers. At the same time, online reviews cover a wide range of contents and diverse forms of expressions, which can effectively stimulate consumers' psychological perception and influence users' decisions on shared short-term rentals.

So far, the related research on shared short-term rentals mainly focused on the operation modes of shared short-term rentals, factors influencing shared short-term rentals, and the impact of shared short-term rentals on traditional hotel industries $[7,9,10]$. Factors affecting shared short-term rental decision include the owner's features, reputation, listing status and location, and rental rules. However, most of the existing explorations of influencing factors are based on websites or tenants, and the results of such explorations cannot well explain the impact of shared customer reviews on consumer decision on shared short-term rentals. At present, there is little work focusing on the internal influencing mechanism of online reviews on users' decisions toward shared short-term rentals. Thus, this paper builds a research model to study the impact of online reviews of shared short-term rentals on users' purchase decisions under the shared economic environment. In particular, this study aims to answer the following questions:

(1) How do online reviews affect users' decisions on shared short-term rentals? What are the internal mechanisms?

(2) Is the impact of online reviews on users' decisions on shared short-term rentals affected by the cognitive needs of users?

Briefly, we make the following contributions in this paper:

(1) We propose a research model that is inspired by the Stimuli-Organism-Response (SOR) model. We set up the quality of online reviews as a stimulus, use perceived sensory and perceived values as organism variables, and let users' decisions on shared short-term rentals be a response variable. In addition, we add the cognitive needs of users as a control variable.

(2) We evaluate users' decisions on Internet-based shared short-term rentals based on the proposed research model and questionnaire data, and present a number of results. The results show that the quality of online reviews influences consumers' perceived value and perceived risk, which in turn impacts users' decisions on shared short-term rentals. In addition, the cognitive needs of consumers can adjust the impact of online reviews on the perceived risk of users. However, it has no explicit adjusting effects between the quality of online reviews and consumers' perceived values.

The remainder of this paper is organized as follows: Section 2 reviews related work. Section 3 presents the theoretical research model and the research hypotheses. Section 4 details the data collection and analysis, and Section 5 discusses research implications and proposes some suggestions for the future development of shared short-tern rentals. Finally, Section 6 concludes the whole paper.

\section{Background and Related Work}

\subsection{Sharing Economy and Shared Short-Term Rentals}

Felson and Speath first proposed the concept of sharing economy [11]. They argued that sharing economy is an information-technology-based marketplace for platforms created by third parties. Individuals can achieve point-to-point direct commodity and service transactions through third-party market platforms. Sharing economy offers users the opportunity to enjoy products without ownership. The widespread use of mobile Internet and online marketing has made sharing economy a sustainable profitable area [1]. Generally, the sharing economy can be divided into three stages. The first stage is code sharing, initiated by Linux. The second stage is content sharing on YouTube or life event sharing 
on Facebook, which is boosted by Web 2.0 and social networks. The third stage is the sharing of offline resources [12]. Houses as a kind of offline resource began to be a sustainable and profitable resource with the rapid development of the sharing economy, because the sharing economy offers house owners opportunities to get economic benefits.

Shared short-term rentals developed with the sharing moving of offline resources. Zervas et al. took the American Airbnb company as an example to study the impact of the short-term rentals on the tourism and accommodation industry [9], which indicated that Airbnb's short-term rentals highly impacted the local hotel industry. As a result, it decreased the revenue of the local traditional hotel industry by 8 to $10 \%$. In order to exploit users' willingness to accept shared short-term rentals, Botsman et al. conducted a study from the perspective of economic motivation and social motivation [12]. They found that the appearing of shared short-term rentals was highly associated with the global economic recession, which caused economic and social pressure and made people consider the cost-effective shared short-term rentals for accommodation. In addition, Liu et al. empirically studied the strategy of online advertising [13]. They found that the attractiveness of shared short-term rental advertisements and the sense of user power interacted with the willingness to click and the willingness to purchase. In recent years, scholars have been keen to explore the impact of landlord photos on users' decisions on shared short-term rentals: Ert et al. used the experimental method to study Airbnb and found that compared with the landlord's reputation, the landlord's photos can influence consumers' shared short-term rental behavior [14]. Zhang et al. and others studied the impact of the source and quality of landlord's photos on the use of housing resources [15]. They found that the platform professionals took more convincing pictures, and high-quality pictures would also increase landlord's income. In addition, they argued the influence of the source and quality of the landlord on the use of the property. They also found that the high-quality images taken by the platform professionals were more convincing which could increase the income of the landlord.

With the rapid development of the Internet, more and more users start to experience online hotel booking on Internet-based hotel reservation platforms such as Booking.com and Ctrip.com. According to a recent study [16], a ten-percent increasing of online reviews on hotel reservation platforms would lead to five-percent increasing of online booking orders. This shows that online reviews are influential to hotel booking. Moreover, a study of Swiss hotels revealed that the number of positive online reviews had a significant positive impact on hotel sales revenue [16,17]. Other researchers [18,19] considered the users' professionalism when quantifying the impact of online reviews on users' decision-making toward hotel booking. In addition, other features like user characteristics that might impact hotel-booking intention were analyzed [20]. In summary, previous studies have shown that online reviews have a significant impact on the sales of the hotel industry. However, differing from existing studies that focused on hotel booking, this paper concentrates on shared short-term rentals. Most of short-term rentals are private apartments. As the features of apartments surely differ from those of hotels, online reviews toward shared short-rentals are also quite different from those toward hotels. To this end, it is reasonable that users purchasing shared short-rentals have varying needs compared to users in the traditional hotel-booking market.

\subsection{Perceived Value and Perceived Risk}

The concept of perceived value was formally proposed by Porter [21]. Perceived value refers to the competitive advantage of a company compared with other competitors. Since then, perceived value has been applied to the research of e-commerce, network shopping, and market development [22,23]. Zeithaml et al. studied perceptual value from a psychological perspective [24]. He believed that perceived value was the overall evaluation of a customer toward a service or a product of a particular company. He also claimed that value was superior to other factors. Further, value can be perceived and was influenced by personal knowledge. To this end, perceived value is subjective.

Perceived value was divided into functional value and emotional value [25]. Later in the field of brand research, Sweeney et al. measured the perceived value of customers of high-end 
durable goods from the four dimensions of emotion, society, quality, and currency [26]. Based on Sweeney's work, Petrick et al. further studied the measurement of perceived value and proposed five dimensions, including quality perception, emotional value perception, currency value, industry cost, and reputation [27].

Another factor that has been extensively studied in the field of e-commerce is perceived risk. Since Bauer proposed the concept of perceived risk of consumers [28], many scholars have discussed the issue and have presented numerous extended definitions. Perceived risk is a possibly previous measure of consumer perceived usefulness and perceived ease of use towards purchasing on the internet. Bauer believed that human behavior was highly uncertain; thus so people's behavior was risking. Due to the inequality of information, users' decisions on shared short-term rentals are also highly uncertain. Cox et al. believed that perceived risk can be divided into two dimensions [29]: one is that consumers may be suspicious of bad consequences before making consumption decisions; the other is the extent to which an accident affects them. People are used to reducing perceived risk before making decisions. For sharing this emerging thing and model, the user's uncertainty may be higher compared to the traditional consumption model, and perceived risk is more valuable for studying user behavior.

So far, there have been a lot of studies toward perceived risk. Peter and Ryan pointed out that people will experience perceived risks from a social, economic and functional perspective [30]. Jacoby et al. argued that the perspective of perception should include five aspects [31]: body (whether user behavior will cause physical damage), property (whether user behavior will cause loss of property), society (whether user behavior will threaten user position), function (whether user behavior will satisfy user's own needs), and psychology (whether use behavior will impact user's emotion). Peter and Tarpey proposed the dimension of time based on the above research [32]. In the shopping environment of the Internet era, Jarvenpaa et al. argued that consumers' perceived risk needs further exploration [33]. They recalibrated the six dimensions to five, which include efficacy level, economic level, security level, privacy level and social level. The level of privacy is based on the new environment. He points out that when consumers consume in the network environment, their personal data will be leaked and used. This perspective is also the product of the new environment. In short, the uncertainty of the consequences of user behavior creates a hesitant state of mind that affects the generation of behavior. Although there are a few existing research on shared services and economy [34], consumer uncertainty may be more serious in the Internet age. The high quality information provided by online reviews may affect the perceived risk of consumers, and further affect users' decisions on shared short-term rentals.

\subsection{Users' Purchase Decisions}

Users' purchase decisions are always an important issue in the field of user behavior [35]. Online reviews are also regarded as a stimulus for consumers to buy share short-term rentals. Positive online reviews will make consumers feel that they can benefit from share short-term rentals, which will guide the purchase behavior of users. User behavior is an act or activity. Nicosica et al. believed that user behavior is a purchase, not a resale [36]. Other researchers claimed that users' purchase-decision behavior is the activity of consumers to choose, use, and process products or services [37]. This includes not only purchase, but also ideas, advice, and actions related to the purchase behavior of users. In this paper, users' decisions on shared short-term rentals are regarded as one kind of purchase behavior. Feeny argued that user behavior is an activity in which users choose, use, or process products or services [38]. Users have temporary use rights for idle houses by booking shared short-term rentals; this behavioral user decision on shared short-term rentals can be regarded as a process. In addition, user behavior can also be a process that encompasses all activities for a product or service [39]. The essence of user behavior is an activity in which consumers satisfy their needs by purchasing products or services. In this paper, the main concern is whether users are engaged in bookings when they are shared short-term rentals. 
Users' purchase decisions refer to the optimal purchase plan that is analyzed, evaluated, selected, and implemented among two or more purchase plans that are available for selection in order to meet a certain demand under the control of certain purchase motivation as well as post-purchase evaluation activities. User purchase decision has been mostly studied in the area of online shopping and social networks [40]. Olbrich et al. analyzed certain social commerce data, and found that products with labels and praise had better sales [41]. In addition, Moody et al. revealed that the seller's reputation, size, amount of information, transaction security, communication, and word-of-mouth had a positive impact on user information and purchase intention [42]. Previous research results showed that the collection and processing of information was an important factor affecting users' purchase intension. In the field of online shopping, users' online reviews posted on platforms are often one of the main sources for user to get information about products. Godes et al. used online reviews as antecedents for decision-making based on users' past experiences [43]. Online review has turned traditional interpersonal communication into online communication. Online reviews spread more widely and faster than traditional product information, and have a deeper impact on sales. In short, there are many factors affecting user behavior, and online review has an important impact on users' purchase intension [44]. In this study, we attempt to reveal the impact as well as the internal mechanism of online reviews on users' decisions on shared short-term rentals.

\section{Research Model and Hypotheses}

\subsection{Research Model}

In 1974, Mehrabian and Russwell proposed the Stimuli-Organism-Response (SOR) model based on environmental psychology [45]. The model is used to explain the relationship between the physical environment and human behavior, consisting of an antecedent variable (Stimulus), a mediator variable (Organism), and a result variable (Response). In the SOR model, $\mathrm{S}$ represents the external environmental stimulus that causes individual response, $\mathrm{O}$ represents the evaluation of the stimulus by the organism or the subject of the response, and $\mathrm{R}$ represents the behavioral response after the evaluation of the stimulus. The SOR model implies that external stimuli affect an individual's behavioral response by affecting the individual's mental state. Eroglu et al. (2003) improved the SOR model for external online shopping scenarios by using online product display as an external stimulus to explore customer online buying behavior from the perspective of online user sentiment and cognitive changes [46].

In this study, we adopt the SOR model as the fundamental research model. We believe that online review on the shared short-term rentals platforms is the external environmental stimulus that causes individual reactions, which affects the individual's psychological perception, i.e., the internal evaluation of shared short-term rentals. Then, users can make purchase decisions. We also use online review as an independent variable to explore the internal mechanism of users' decision behavior of shared short-term rentals through the mediating role of perceived risk and perceived value of users. In addition, this paper attempts to explore the moderating effect of online reviews on users' psychological perception.

Figure 1 shows the research model of this study, which mainly measures the relationship between the quality of online reviews and users' decisions on shared short-term rentals. The higher the quality of online reviews, the more complete the information provided, and the more effective it is to stimulate users' behavior. For the intermediary variables, we mainly measure two aspects of user perception, namely perceived value and perceived risk. Shared short-term rentals, when compared with traditional city hotels, have higher uncertainty because of the less understanding of users on shared short-term rentals.

We also introduce a new moderating variable called cognitive needs of users (shown as cognitive need in Figure 1). That is because the personality characteristics of users are the main adjustment factors to shared short-term rentals. In general, if the information obtained by users is more complete, 
the perceived value is higher and the perceived risk is lower. However, this depends on users' personal cognitive needs.

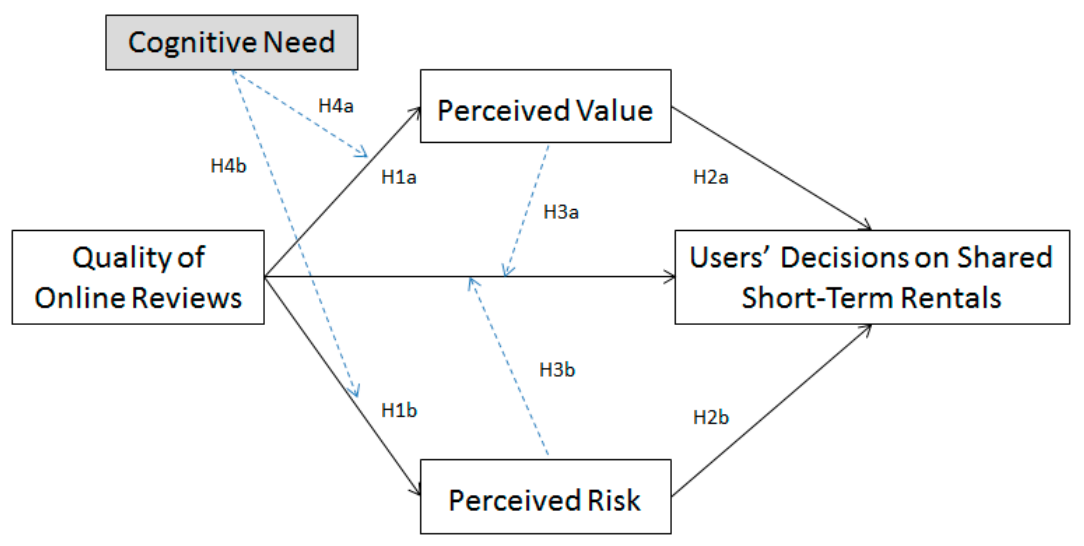

Figure 1. The research model.

Cognitive needs refer to the process in which users participate in thinking and enjoying thinking in the process of understanding things. Users with high cognitive needs are eager to get more information about product attributes, which can help them make decisions. Table 1 summarizes the variables of this research model.

Table 1. Variables in the research model.

\begin{tabular}{ccc}
\hline Role & Variable & Description \\
\hline Independent Variable & Quality of Online Reviews & $\begin{array}{c}\text { Users can find the information they need in high-quality } \\
\text { online reviews. }\end{array}$ \\
\hline Mediating Variables & Perceived Value & $\begin{array}{c}\text { High-quality online reviews can perceive the value of } \\
\text { choosing to share short rents. }\end{array}$ \\
\cline { 2 - 3 } Dependent Variable & Perceived Risk & $\begin{array}{c}\text { High-quality online reviews can reduce } \\
\text { user uncertainty. }\end{array}$ \\
\hline Moderating Variable & Short-Term Rentals & $\begin{array}{c}\text { When choosing hotels, users make short-rent } \\
\text { reservation on shared short-rental platform. }\end{array}$ \\
\hline Cognitive Need & $\begin{array}{c}\text { The regulatory role of user personality characteristics in } \\
\text { the relationship between online reviews and } \\
\text { user perception. }\end{array}$ \\
\hline
\end{tabular}

\subsection{Research Hypothesis}

Users' decisions on shared short-term rentals have a major impact on the development of shared short-term rental platforms. Therefore, it is necessary to explore the factors that influence users' decisions on shared short-term rentals. Online reviews are one of the important factors that affect users' online shopping behavior. Previous work has demonstrated the impact of online reviews on hotel accommodation sales and users' decision-making $[47,48]$.

According to the research model shown in Figure 1, the quality of online reviews as an independent variable affects users' decisions on shared short-term rentals by affecting users' perceived value and perceived risk. In order to explain the internal mechanism of online reviews on the impact of users' decisions on shared short-term rentals, we first set up the following questions, as shown in Table 2. The Q1 question is to find out the influential relationship between independent variables and the mediating variable. The Q2 question is to find out the influential relationship between the mediating variables and the dependent variable. The Q3 question aims to find out the intermediate relationship among all the factors in the research model. Finally, the Q4 question is to find out what effect the moderating variable has on the relationship between independent variables and mediating variables. 
Table 2. Research questions and corresponding hypotheses.

\begin{tabular}{clc}
\hline Question Number & \multicolumn{1}{c}{ Research Question } & Corresponding Hypotheses \\
\hline Q1 & $\begin{array}{l}\text { What influences exist between independent } \\
\text { variables and the mediating variable (perceived } \\
\text { value and perceived risk)? }\end{array}$ & $\mathrm{H} 1 \mathrm{a}, \mathrm{H} 1 \mathrm{~b}$ \\
$\mathrm{Q} 2$ & $\begin{array}{l}\text { How does the mediating variable (perceived } \\
\text { value and perceived risk) impact the dependent } \\
\text { variable (users' decisions on shared } \\
\text { short-term rentals)? }\end{array}$ & $\mathrm{H} 2 \mathrm{a}, \mathrm{H} 2 \mathrm{~b}$ \\
\hline $\mathrm{Q} 3$ & $\begin{array}{l}\text { How does a factor in the research model play } \\
\text { intermediate role between other factors? }\end{array}$ & $\mathrm{H} 3 \mathrm{a}, \mathrm{H} 3 \mathrm{~b}$ \\
\hline & $\begin{array}{l}\text { What effect does the moderating variable } \\
\text { (cognitive need) have on the relationship } \\
\text { between independent variables (quality of } \\
\text { online reviews) and intermediate variables } \\
\text { (perceived value and perceived risk)? }\end{array}$ & $\mathrm{H} 4 \mathrm{a}, \mathrm{H} 4 \mathrm{~b}$ \\
\hline
\end{tabular}

Previous studies have pointed out that perceived value is the ratio between the total revenue of a product or service users get from their purchase and the total cost they pay for it [24]. The results showed that the high information quality provided by websites leads to lowness of users' perception on costs as well as the increasing of the perceived value of users. According to these studies, in the sharing economy environment, the high quality of online reviews displaying on shared short-term rentals platforms indicates that platforms can offer high quality information, which can therefore lower the perceived cost of users and increase the perceived value of users.

On the other hand, perceived risk is also the subjective feeling of users, referring to the uncertainties and negative consequences that users perceive subjectively in purchase activities. Murray et al. showed that when potential users perceived high risk in the shopping process [49], they tended to use Internet word-of-mouth to search for relevant products or services. Through summarizing the research literature on the influencing factors of perceived risk of online shopping at home and abroad, we found that perceived risk of consumers mainly comes from three aspects: individual factors (gender, involvement degree, etc.), product factors (product type, brand, etc.) and environmental factors (economy, culture, etc.) Since online reviews reflect users' experiences in the real world, we can reasonably assume that online reviews are more reliable than the information provided by shared short-term rentals platforms. Thus, users are likely to refer to online reviews when they try to make a decision.

In order to answer these questions, we set up several hypotheses:

Hypothesis (H1a): In shared short-term rentals, the high quality of online reviews will increase the perceived value of users.

Hypothesis (H1b): In shared short-term rentals, the high quality of online reviews will lower the perceived risk of users.

Users' decisions on shared short-term rentals also follow the general process of user behavior, meaning that users undertake complex psychological activities under the influence of external stimuli and finally make behavioral decisions. In the study of the relationship between online reviews and user behavior, some scholars believed that online reviews had an impact on user behavior. What really work are not online reviews themselves, but the subjective psychological perception that users form after reading online reviews, including perceived value and perceived risk. Specifically, when choosing to use shared short-term rentals, users' psychological perception directly affects users' decisions on shared short-term rentals. Thus, we make the following hypotheses. 
Hypothesis (H2a): User perceived value has a significant impact on users' decisions on shared short-term rentals.

Hypothesis (H2b): User perceived risk has a significant impact on users' decisions on shared short-term rentals.

In addition, Sussman et al. integrated the elaboration likelihood model (ELM) and the technology acceptance model (TAP) and proposed an online review information adoption model [50]. This model mainly analyzes the influence of users' adoption of online review information on their consumption decision-making behavior in the network environment. They also proposed to use perceptual value as a mediating factor in the relationship between online review quality and user behavior of travel decision-making. In addition, Miyazaki et al. pointed out that the perceived risk is negatively correlated with user consumption behavior through the study of perceived risk antecedent variables [51]. Users' psychological perception is the subjective attitude of people. When reading the same online reviews, users' psychological perceptions may be different, which leads to different decision-making behavior. In other words, in the context of sharing economy, users' psychological perception may play a mediating role in the relationship between online reviews and users' decisions on shared short-term rentals. Thus, we make the following hypotheses:

Hypothesis (H3a): The perceived value of users plays a mediating role between online reviews and users' decisions on shared short-term rentals.

Hypothesis (H3b): The perceived risk of users plays a mediating role between online reviews and users' decisions on shared short-term rentals.

Next, we consider that the influence of online reviews on users' psychological perception. We guess that users' psychological perception depends not only on the characteristics of online reviews, but also on the characteristics of recipients. This is because users may have different personality characteristics and attitudes towards online reviews, which may lead to different user purchase decision. Cognitive needs refer to the process in which an individual participates in and enjoys thinking in the process of recognizing things. Users with high cognitive needs are eager to get more information about product attributes that can help them make decisions. Cacioppo et al. carried out experiments to measure the level of cognitive needs [52]. They found that people can be divided into two categories: a group of people with low cognitive needs, who think that the situation should be orderly and regular, and another group of people with high cognitive needs who think that the situation is not clear and they will analyze the situation according to personal experience to understand the situation. Cacioppo et al. also pointed out that people with high cognitive needs prefer to think and form a brand attitude through thinking. On the contrary, people with low cognitive needs are susceptible to the side-effects of advertising. That is to say, people with different cognitive needs have different ways of processing information. In general, the information about the products with high-quality online reviews is more about post-consumer experiences and feelings, which can meet the needs of users with low cognitive needs and fasten decision-making processes. In summary, because of high-quality online reviews, users with low cognitive needs may get high perceived value and lower perceived risk. Thus, we make the following hypotheses:

Hypothesis (H4a): Cognitive needs play a moderating role during the process where online reviews impact perceived value.

Hypothesis (H4b): Cognitive needs play a moderating role during the process where online reviews impact perceived risk. 


\section{Data Collection and Analysis}

\subsection{Questionnaire Design}

We used a questionnaire to test the hypotheses. Specially, we design the questionnaire according to the general principles and steps of the literature. Firstly, the indicators of each variable were extracted through a great number of literature studies, and the designed questionnaires were tested on a small scale among 28 college students who had rented a house on the Internet shared short-term rental platforms. Some of the items were revised according to the results of the small sample analysis, and the formal research questionnaire was finally formed through repeated revisions. The questionnaire consists of three parts:

(1) Information about user travelling experiences. This section focuses on general information about user travelling, including the frequency of experiencing shared short-term rentals, the frequency of travelling, and the type of accommodation.

(2) Basic information about users. This part of questionnaire includes the gender, age, and educational background of the surveyed users.

(3) Questionnaire on independent variable, mediating variable, dependent variable and moderating variable, which is the core of the whole questionnaire. The sources of variables are as follows. The online review quality scale comes from the previous studies $[53,54]$. The risk-aware scale was designed according to the literature $[55,56]$. The perceptual value scale was developed according to the literature [57]. The scale of user shared short-term rentals is based on the scale developed by Fishbein and Bansal $[58,59]$. The scale of cognitive needs was modified according to the scale designed by Cacioppo [52].

The questionnaire was designed according to the Likert five-point scale, and the respondent was asked to choose a score ranging from 1 (totally disagree) to 5 (totally agree) to answer each question. The details of the questionnaire are shown in Table 3.

\subsection{Data Collection}

The data collection of this study was conducted by an online questionnaire, mainly through the WeChat circle of friends. The product introduction of the shared short-term rental platforms is detailed on the homepage of the questionnaire. The participants are required to have an Internet accommodation booking experience. After screening the questionnaire and eliminating the items that do not have online accommodation booking experiences, we finally obtained 232 valid questionnaires. Baumgartner and Homburg proposed that the number of samples required for a structural equation analysis is at least five times the estimated parameter [60]. Since the research model in this study involves 18 parameters, we need at least 90 samples. Thus, the number of collected samples can satisfy the data analysis. The descriptive statistics of the samples are as follows: 121 males and 111 females, whose age is mostly within the range from 20 to 25 years (85.7\%). In addition, $77.5 \%$ of participants hold a college degree. 
Table 3. Indicators of the questionnaire.

\begin{tabular}{|c|c|c|}
\hline Construct & Question Code & Measurement Problem \\
\hline \multirow{4}{*}{$\begin{array}{l}\text { Quality of Online } \\
\text { Reviews }\end{array}$} & QU1 & Those online reviews are reliable. \\
\hline & QU2 & These online reviews are detailed and detailed. \\
\hline & QU3 & $\begin{array}{l}\text { These online reviews are closely related to the } \\
\text { characteristics of shared short rental itself. }\end{array}$ \\
\hline & QU4 & Overall, online reviews are of high quality and useful. \\
\hline \multirow{3}{*}{ Perceived value } & VA1 & $\begin{array}{l}\text { Online reviews accurately reflect the true quality of } \\
\text { shared short rentals. }\end{array}$ \\
\hline & VA2 & $\begin{array}{l}\text { Online reviews can make me feel that the introduction of } \\
\text { shared short rentals is true. }\end{array}$ \\
\hline & VA3 & Online reviews can help me better perceive products. \\
\hline \multirow{3}{*}{ Perceived risk } & RI1 & $\begin{array}{l}\text { These comments are a good way to assess the economic } \\
\text { risks of purchases. }\end{array}$ \\
\hline & RI2 & $\begin{array}{l}\text { These reviews are a good way to assess whether the } \\
\text { product description is true or not. }\end{array}$ \\
\hline & RI3 & $\begin{array}{l}\text { These comments are a good way to avoid the risk that I } \\
\text { would be laughed at for making a mistake. }\end{array}$ \\
\hline \multirow{4}{*}{ Cognitive needs } & KN1 & $\begin{array}{l}\text { I have a strong interest in the shared short-term rental I } \\
\text { want to book. }\end{array}$ \\
\hline & KN2 & I like to do things that require a lot of thinking. \\
\hline & KN3 & I like to do complicated things instead of simple things. \\
\hline & KN4 & $\begin{array}{l}\text { I will know some housing conditions and the } \\
\text { surrounding environment before buying. }\end{array}$ \\
\hline \multirow{4}{*}{$\begin{array}{c}\text { Users' Decisions on } \\
\text { Shared Short-Term } \\
\text { Rentals }\end{array}$} & SR1 & $\begin{array}{l}\text { These online reviews are helpful for my purchase } \\
\text { decision. }\end{array}$ \\
\hline & SR2 & $\begin{array}{l}\text { I will refer to these comments if I choose to share } \\
\text { short-term rentals. }\end{array}$ \\
\hline & SR3 & $\begin{array}{c}\text { Online review makes me more confident when I am } \\
\text { determined to book a short-term rental }\end{array}$ \\
\hline & SR4 & $\begin{array}{c}\text { Online review have an impact on when I booked a shared } \\
\text { short-term rental }\end{array}$ \\
\hline
\end{tabular}

\subsection{Factor Analysis}

In this section, we use the confirmatory factor analysis (CFA) to analyze the reliability and validity of factors. This paper first uses the SPSS 22.0 software (IBM, Armonk, NY, USA) to conduct the reliability analysis. The results are shown in Table 4. The value of KMO (Kaiser-Meyer-Olkin) is 0.874 , and the Bartlett spheroid test results are significant $($ sig. $=0.000)$. The Bahrain alpha coefficient (Cronbach's $\alpha$ ) and the composite reliability are mostly greater than 0.8 , indicating that the scale has high reliability.

The normalized factor load of the seven explicit variables of the model is higher than 0.8 and reaches a significant level. The CR value is greater than 0.7, and the AVE rate is greater than 0.5. Overall, the model meets the requirements for convergence and validity.

Next, we perform the discriminant validity test. Discriminant validity is proposed to examine whether a measurement is a reflection of any other measurement. As shown in Table 5, the correlation coefficient of each variable is smaller than the square root of the mean variance extraction rate of its corresponding variable, indicating that the discriminant validity is satisfied. 
Table 4. Reliability and validity analysis on variables.

\begin{tabular}{|c|c|c|c|c|c|}
\hline Variable & $\begin{array}{l}\text { Observation } \\
\text { Variable }\end{array}$ & Factor load & Cronbach's $\alpha$ & $\begin{array}{c}\text { Composite } \\
\text { Reliability (CR) }\end{array}$ & $\begin{array}{l}\text { Average Variance } \\
\text { Extracted (AVE) }\end{array}$ \\
\hline \multirow{4}{*}{$\begin{array}{c}\text { Quality of } \\
\text { Online Reviews }\end{array}$} & QU1 & 0.73 & \multirow{4}{*}{0.878} & \multirow{4}{*}{0.876} & \multirow{4}{*}{0.639} \\
\hline & QU2 & 0.76 & & & \\
\hline & QU3 & 0.88 & & & \\
\hline & QU4 & 0.82 & & & \\
\hline \multirow{3}{*}{ Perceived value } & VA1 & 0.80 & \multirow{3}{*}{0.818} & \multirow{3}{*}{0.832} & \multirow{3}{*}{0.609} \\
\hline & VA2 & 0.76 & & & \\
\hline & VA3 & 0.78 & & & \\
\hline \multirow{3}{*}{ Perceived risk } & RI1 & 0.76 & \multirow{3}{*}{0.737} & \multirow{3}{*}{0.774} & \multirow{3}{*}{0.533} \\
\hline & RI2 & 0.71 & & & \\
\hline & RI3 & 0.72 & & & \\
\hline \multirow{4}{*}{$\begin{array}{l}\text { Cognitive } \\
\text { needs }\end{array}$} & KN1 & 0.80 & \multirow{4}{*}{0.842} & \multirow{4}{*}{0.852} & \multirow{4}{*}{0.592} \\
\hline & KN2 & 0.84 & & & \\
\hline & KN3 & 0.72 & & & \\
\hline & KN4 & 0.71 & & & \\
\hline \multirow{4}{*}{$\begin{array}{c}\text { Shared } \\
\text { Short-Term } \\
\text { Rental Decision }\end{array}$} & SR1 & 0.85 & \multirow{4}{*}{0.886} & \multirow{4}{*}{0.881} & \multirow{4}{*}{0.649} \\
\hline & SR2 & 0.80 & & & \\
\hline & SR3 & 0.81 & & & \\
\hline & SR4 & 0.76 & & & \\
\hline
\end{tabular}

Table 5. Discriminant validity test.

\begin{tabular}{|c|c|c|c|c|c|}
\hline & $\begin{array}{c}\text { Quality of Online } \\
\text { Reviews }\end{array}$ & $\begin{array}{l}\text { Perceived } \\
\text { Value }\end{array}$ & $\begin{array}{l}\text { Perceived } \\
\text { Risk }\end{array}$ & $\begin{array}{l}\text { Cognitive } \\
\text { Needs }\end{array}$ & $\begin{array}{c}\text { Users' Decisions on } \\
\text { Shared Short-Term } \\
\text { Rentals }\end{array}$ \\
\hline $\begin{array}{c}\text { Quality of Online } \\
\text { Reviews }\end{array}$ & 0.799 & & & & \\
\hline Perceived Value & 0.717 & 0.780 & & & \\
\hline Perceived Risk & -0.443 & -0.424 & 0.730 & & \\
\hline Cognitive Needs & 0.647 & 0.681 & -0.467 & 0.769 & \\
\hline $\begin{array}{l}\text { Users' Decisions on } \\
\text { Shared Short-Term } \\
\text { Rentals }\end{array}$ & 0.690 & 0.749 & -0.517 & 0.735 & 0.805 \\
\hline
\end{tabular}

\subsection{Structural Model Evaluation}

The structural model measures the relationship between latent variables. The path coefficients between the latent variables in the study model were verified using AMOS 23.0 (IBM, Armonk, NY, USA). The path coefficient values between the variables are shown in Figure 2.

When users subscribe to shared short-term rentals, the quality of online reviews significantly affects users' perceived value $(\beta=0.84, p<0.01)$, assuming H1a is verified. This shows that the quality of online reviews can significantly improve the perceived value of users when users subscribe to shared short-term rentals. When users subscribe to shared short-term rentals, the quality of online reviews significantly affects visitors' perceived risk $(\beta=-0.55, p<0.01)$, assuming $\mathrm{H} 2 \mathrm{~b}$ is verified. This shows that the quality of online reviews can reduce the perceived risk of users. This may be due to the fact that when visitors receive higher quality online reviews, users get more information with more value, less uncertainty, perceived cost of decline, and thus higher perceived value and perceived risk. 


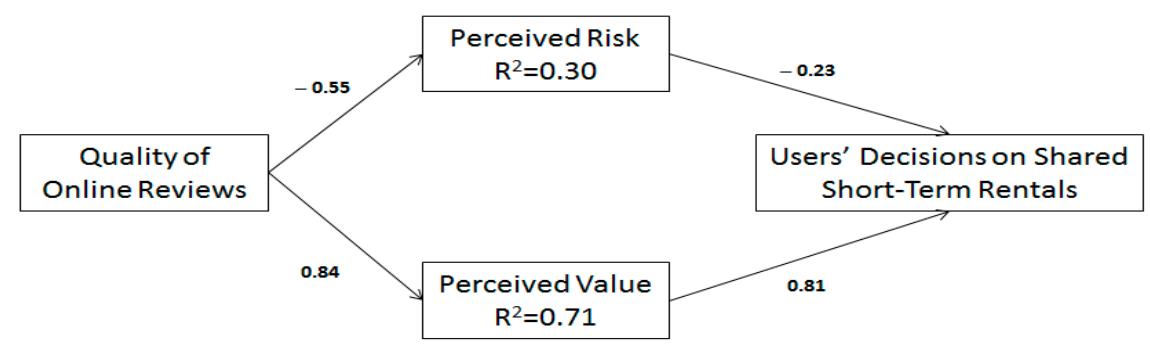

Figure 2. The path coefficient values between the variables for structural model evaluation.

The perceived value of users has a significant impact on users' decisions on shared short-term rentals ( $\beta=0.81, p<0.01$ ), assuming H2a is verified. This shows that the perceived value of users is positively related to users' decisions on shared short-term rentals. In addition, the perceived risk of users has a significant impact on users' decisions on shared short-term rentals $(\beta=-0.23, p<0.01)$. This shows that users' perceived risk is negatively correlated with users' decisions on shared short-term rentals. Perceived value and perceived risk are subjective feelings of people, which means that users may be affected by various stimulating factors, resulting in the change of perceived value and perceived risk, and in turn the decision behavior of users.

In addition, the permissible coefficients of perceived value and perceived risk are 0.71 and 0.30 , respectively. This indicates that the quality of online reviews explains the variance variation of $71 \%$ of the perceived value generated by users' online bookings for shared short-term rentals. The quality of online reviews explains the perceived risk by $30 \%$ variance variation. As a result, the model explains the $84 \%$ variance variation of users' decisions on shared short-term rentals, showing that the degree of interpretation is satisfied. Table 6 shows the model fitting results. The descriptions of the symbols shown on the first row are provided in Table 7.

Table 6. Model fitting results.

\begin{tabular}{cccccccccccc}
\hline Statistical Test & $\boldsymbol{X}^{2} / d f$ & SMRM & RMSEA & AGFI & NFI & RFI & CFI & IFI & PGFI & PNFI & PCFI \\
\hline Ideal Standard Value & $<2.00$ & $<0.08$ & $<0.05$ & $>0.80$ & $>0.90$ & $>0.90$ & $>0.90$ & $>0.90$ & $>0.50$ & $>0.50$ & $>0.50$ \\
\hline Acceptable Standard & $<3.00$ & $<0.1$ & $<0.08$ & $>0.70$ & $>0.80$ & $>0.80$ & $>0.80$ & $>0.80$ & & & \\
\hline Results of This Study & 1.712 & 0.056 & 0.056 & 0.893 & 0.938 & 0.922 & 0.973 & 0.973 & 0.700 & 0.752 & 0.780 \\
\hline
\end{tabular}

Table 7. Explanations of the symbols used in Table 6.

\begin{tabular}{cc}
\hline Symbol & Description \\
\hline$X^{2}$ & Chi square statistic \\
\hline$d f$ & Degrees of freedom \\
\hline SMRM & Standardized root mean squared \\
\hline RMSEA & Root-mean-square error of approximation \\
\hline AGFI & Adjusted goodness-of-fit index \\
\hline NFI & Normed fit index \\
\hline RFI & Relative fit index \\
\hline CFI & Comparative fit index \\
\hline IFI & Incremental fit index \\
\hline PGFI & Parsimonious goodness-of-fit index \\
\hline PNFI & Parsimonious normed fit index \\
\hline PCFI & Parsimonious comparative fit index \\
\hline
\end{tabular}




\subsection{Mediating Effect Test}

In order to verify the intrinsic mechanism of the impact of online-review quality on users' decisions on shared short-term rentals, we use the bootstrap method (Bootstrap) for mediation analysis (sample size is set to 2000) [61]. Thus, it is judged whether the mediating effects of perceived value and perceived risk exist. The results are shown in Table 8 . We can see that under the $95 \%$ confidence interval (CI), the bias-corrected, percentile, and PRODCLIN2 testing results show that perceive value and perceived risk have a mediating effect in the research model.

Table 8. Coefficient products and bootstrapping checking results.

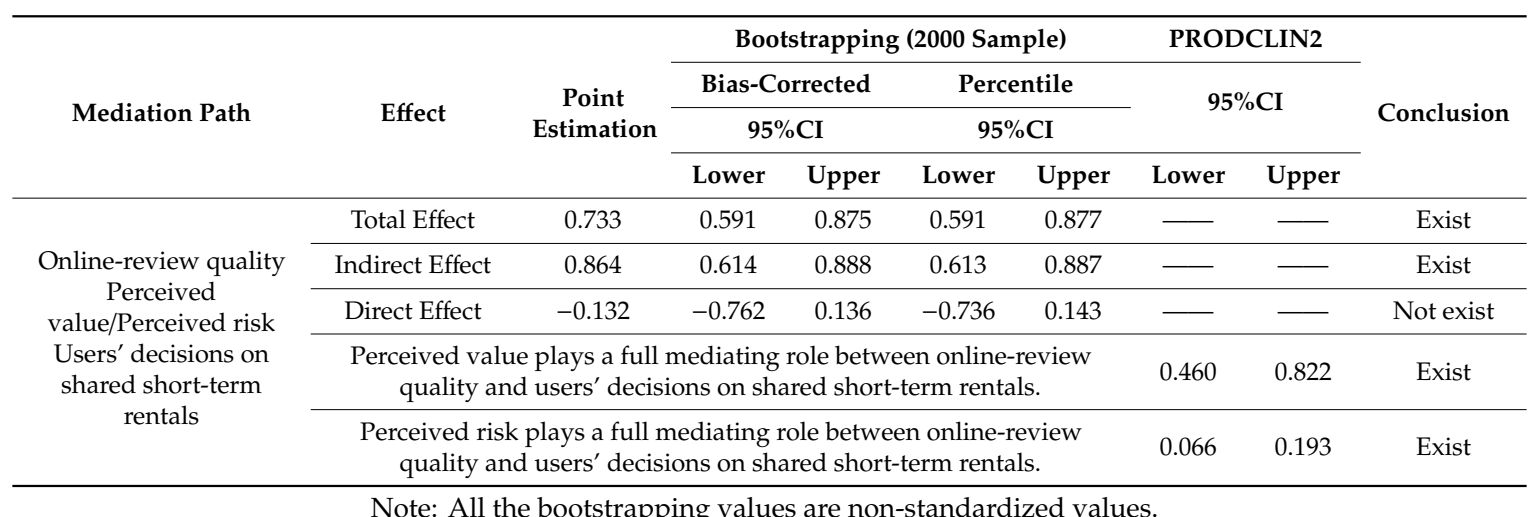

Note: All the bootstrapping values are non-standardized values.

In summary, there is a complete mediation between perceived value and perceived risk in the decision-making path of online-review quality affecting users' decisions on shared short-term rentals. This shows that the quality of online reviews mainly affects the perceived value and perceived risk of users' psychology, and further affect users' decisions on shared short-term rentals. Both perceived value and perceived risk have a dual intermediary role between online-review quality and users' decisions on shared short-term rentals, demonstrating the validity of H3a and H3b.

\subsection{Moderating Effect Test}

In this section, we test the moderating effect of the moderating variable. Here, SPSS 20 is used to conduct the test by using the hierarchical regression method (HRM). The results show that the variance inflation factors (VIF) of the related variables are all less than 2, indicating that there is less information overlap between explanatory variables and there is no serious multicollinearity problem between variables.

Table 9 shows the moderating effect of user cognitive needs. We can see that the moderating effect of users' cognitive needs between online-review quality and perceived value does not exist. Meanwhile, user cognitive need has a moderating effect between online-review quality and perceived risk. Therefore, the hypothesis $\mathrm{H} 4 \mathrm{a}$ is not valid, but the hypothesis $\mathrm{H} 4 \mathrm{~b}$ is verified. For people with different cognitive needs, the valuable information provided is the same, so the change of perceived value is not significant. On the other hand, the quality of online reviews indirectly proves the authenticity of information provided by platforms, which can reduce the perception of users' uncertainty. The reduction of users' uncertainty leads to the reduction of users' perceived risk. Compared with users with low cognitive needs who are eager to make decisions as soon as possible, users with high cognitive needs still need more information to help them verify the authenticity of their information and make decisions. Therefore, the perceived risk of users with high cognitive needs decreases at a slow rate with the improvement of online-review quality, which means that cognitive needs have a significant moderating effect between online-review quality and perceived risk. 
Table 9. Moderating effect testing results of cognitive needs.

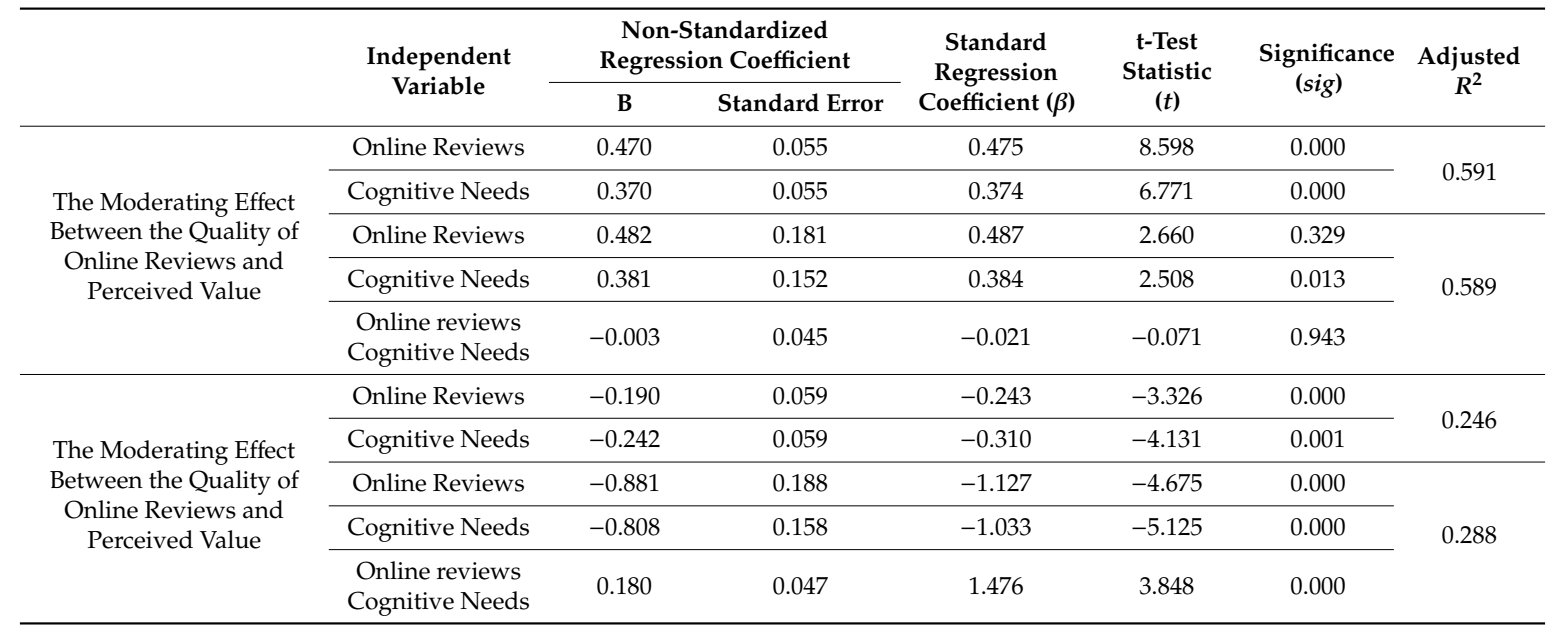

\subsection{Summary of Hypotheses Validation}

Based on the results described in Sections 4.1-4.6, we present the summary of the hypotheses validation in Table 10. The validation-result column in Table 9 shows the final validation results of each hypothesis. The hypotheses $\mathrm{H} 1 \mathrm{a}, \mathrm{H} 1 \mathrm{~b}, \mathrm{H} 2 \mathrm{a}$, and $\mathrm{H} 2 \mathrm{~b}$ are all established. These assumptions correspond to our Q1 and Q2. This means that the quality of online reviews, which is the independent variable in our research model, has a positive impact on users' decisions on shared short-term rentals. $\mathrm{H} 4 \mathrm{~b}$ has also been verified, and $\mathrm{H} 4 \mathrm{a}$ has not been verified, which corresponds to our Q3. This means that the personality characteristics of users can influence users' internal perception of online reviews. The main impact is the perceived risk of users, and its moderating effect on the perceived value is not significant. Platforms should pay more attention to the personality characteristics of users and adopt relevant marketing strategies to reduce users' perceived risks. Regarding the hypotheses of H3a, $\mathrm{H} 3 \mathrm{~b}$, which aim to answer the research question of Q4, the results show that both perceived value and perceived risk play a full intermediary role between online-review quality and users' decisions on shared short-term rentals. Therefore, platforms should focus on user psychological perception and promote users' decisions on shared short-term rentals.

Table 10. Summary of hypotheses validation.

\begin{tabular}{ccc}
\hline Number & Hypothesis & Validation Result \\
\hline $\mathrm{H} 1 \mathrm{a}$ & $\begin{array}{c}\text { In shared short-term rentals, the high quality of online reviews } \\
\text { will increase the perceived value of users. }\end{array}$ & Established \\
\hline $\mathrm{H} 1 \mathrm{~b}$ & $\begin{array}{c}\text { In shared short-term rentals, the high quality of online reviews } \\
\text { will lower the perceived risk of users. }\end{array}$ & Established \\
\hline $\mathrm{H} 2 \mathrm{a}$ & $\begin{array}{c}\text { User perceived value has a significant impact on users' decisions } \\
\text { on shared short-term rentals. }\end{array}$ & Established \\
$\mathrm{H} 2 \mathrm{~b}$ & $\begin{array}{c}\text { User perceived risk has a significant impact on users' decisions } \\
\text { on shared short-term rentals. }\end{array}$ & Established \\
\hline $\mathrm{H} 3 \mathrm{a}$ & $\begin{array}{c}\text { The perceived value of users plays a mediating role between } \\
\text { online reviews and users' decisions on shared short-term rentals. }\end{array}$ & Established \\
\hline $\mathrm{H} 3 \mathrm{~b}$ & $\begin{array}{c}\text { The perceived risk of users plays a mediating role between } \\
\text { online reviews and users' decisions on shared short-term rentals. }\end{array}$ & Established \\
\hline $\mathrm{H} 4 \mathrm{a}$ & $\begin{array}{c}\text { Cognitive needs play a moderating role during the process } \\
\text { where online reviews impact perceived value. }\end{array}$ & Not established \\
\hline $\mathrm{H} 4 \mathrm{~b}$ & $\begin{array}{c}\text { Cognitive needs play a moderating role during the process } \\
\text { where online reviews impact perceived risk. }\end{array}$ & Established \\
\hline
\end{tabular}




\section{Discussion}

\subsection{Research Implications}

First, in this study, we employ the SOR model to explore the internal mechanism of online reviews on users' decisions on shared short-term rentals. This model expands the application scope of the SOR model and provides referential values for other related research. In addition, we also presented empirical results that reflecting the impact of online reviews on users' decisions on shared short-term rentals, which can provide a new perspective for promoting shared short-term rentals and new marketing mechanisms.

Second, this paper studied the factors impacting shared short-term rental decisions, and provided referential values for enterprises to increase users' willingness to be engaged in today's mobile internet enabled sharing economy. Our study reveals that online reviews can inspire users' decisions on shared short-term rentals.

Third, we used perceived value and perceived risk as a mediator between online reviews and users' decisions on shared short-term rentals. The empirical results show that perceived value and perceived risk can influence users' decisions on shared short-term rentals. In addition, both perceived value and perceived risk play a full intermediary role between online reviews and users' decisions on shared short-term rentals. Therefore, the sharing of short-term rental platforms needs to pay attention to the psychological perception of users. Moreover, platforms need to reduce the perceived risk of users and increase the perceived value of users.

Fourth, regarding the measurement of users' personality characteristics, this paper mainly focused on users' cognitive needs. The results show that cognitive needs play a moderating role in the relationship between online reviews and perceived risk. Users with high cognitive needs need better information to reduce their perceived risk. Thus, users need more information from the Internet to reduce their uncertainty. Therefore, shared short-term rental platforms should provide users with more opportunities to communicate on the basis of correctly guiding online reviews.

Fifth, the data used in this paper are mainly from surveys of young people. Our research shows that young people can quickly accept a new type of city accommodation such as shared short-term rentals. Therefore, how to improve young people's choice of shared short-term rentals is what a shared short-term rental platform should consider. Many people are struggling to find a hotel around their destination when they have a temporarily traveling. Due to geographical locations and other issues, the traffic around the hotel may be inconvenient. Based on the wide range of sources of tenants on the shared short-term rental platform, when users post accommodation requirements or choose accommodation, they can easily choose the right place to stay. To this end, shared short-term rental platforms still have spaces and potentials for further development.

In summary, the main conclusions of this study, i.e., online reviews are highly influential to users' decision-making behavior, are coherent with previous works [17,19]. However, in the traditional hotel industry, the studies about online reviews and users' purchasing intention mainly focused on the characteristics of hotels and users. On the contrary, this paper is mainly toward online reviews on shared short-term rentals, which typically refer to private apartments advertised by owners on Internet-based rental platforms. Apartments have different features from hotels, and users engaged in shared short-term rentals are also much different from those choosing hotel booking. For example, many young students are likely to try shared short-term rentals, while most business people prefer high-standard hotels. Based on these differences, we set up new variables for the SOR research model. Specially, we focus on the mediating effect of users' perceived value and perceived risk, because users choosing shared short-term rentals have to balance their perceived values and possible risks. On the other hand, although shared short-term rentals as a new kind of shared economy have received much attention in recent years, there are few previous studies that focus on the impact of online reviews on users' purchasing decision on shared short-term rentals. We believe that the main conclusions of this paper can provide referential values for further studies in this field. 


\subsection{Suggestions}

Based on the empirical analysis of this study, we provide the following suggestions for better implementation of shared short-term rental platforms.

(1) Guide users to provide effective online reviews.

The quality of online reviews significantly affects users' decisions on shared short-term rentals. On the one hand, the higher the quality of online reviews, the richer the review content, the higher the perceived value of users, and the lower the perceived risk. On the other hand, platforms should appropriately encourage purchased users to comment on the shared rentals, so that users with low cognitive needs can make up useful suggestive strategies. At the same time, platforms should guide users to provide product information that the website has not yet paid attention to, so as to help users with high cognitive needs to make decisions.

(2) Create topics and provide material rewards for online reviews.

By creating topics and rewarding material prizes, platforms can effectively guide the review content, direction, and quantity of online reviews. According to previous research, the number of online reviews positively affects users' willingness to purchase. More online reviews imply that more potential users will be able to learn more product-related information and be able to better perceive products. If there are many online reviews with high quality, shared rental platforms will attract more attention of users. In order to do so, platforms are suggested rewarding users with little gifts to encourage users to share short-term rental photos or experiences, so that the quality and quantity of online reviews can be improved.

(3) Provide better qualified rental products and services.

We suggest that shared short-term rental platforms provide qualified rental products and services to ensure that users can experience shared short-term rentals with their psychological expectations. The products and services provided by platforms can directly affect the perceived value of users. This is because shared rental industry is actually a service-oriented industry. So shared rental platforms should not only provide shared short-term housing, but also provide services related to the products, such as route planning, traffic information, and information about surrounding sightseeing places. This will increase the perceived value of users and has a significant positive impact on users' decisions on shared short-term rentals.

\section{Conclusions and Future Work}

In this paper, we empirically investigated the impact of online reviews on users' decisions toward shared short-term rentals in the context of social networks, sustainable tourism, and sharing economy. Our study found that the quality of online reviews significantly affects users' perceived value, and negatively affects perceived risk. In addition, both perceived value and perceived risk have a dual intermediary role between online-review quality and users' decisions on shared short-term rentals. We also studied the moderating effect of the cognitive needs of users. We found that the moderating effect of user cognitive needs between online-review quality and perceived value does not exist. Meanwhile, user cognitive need has a moderating effect between online-review quality and perceived risk.

Some limitations of this study can be summarized as follows. First, although hundreds of valid questionnaires are theoretically enough to conduct data analysis, in this big data era, this number is relatively small to draw reliable and robust conclusions. Second, the results of this study have shown that online reviews have positive impact on users' decisions on shared short-term rentals. However, the inherent theoretical basis has not been revealed yet.

Thus, in the future there are some research issues that are worth further investigating. First, in terms of the impact of review quality on the purchase intention of short-term rentals, secondary 
data collected from home sharing platforms like Airbnb could be a better choice. One possible way is to conduct text mining of the reviews of each property to measure review quality monthly, and to use the review volume to predict the purchase intention of each property. Second, because users' decision-making behavior could be impacted by other factors, future work can be focused on other possible factors, such as users' income and education background, review volume or variance, and users' online experience. Finally, it is also worth to study other research models [62] on user acceptance and consider online reviews within the community context [63].

Author Contributions: J.Z.: Conceptualization, Project administration, Supervision, and Writing-original draft, Z.P.: Data curation, Formal analysis, Investigation, and Software.

Funding: This paper is partially supported by the National Science Foundation of China (No. 71273010) and the Innovation Team Construction Project of Anhui University.

Acknowledgments: We would like to thank the editors and anonymous reviewers for their suggestions and comments to improve the quality of the paper.

Conflicts of Interest: The authors to declare no conflict of interest.

\section{References}

1. Sutherland, W.; Jarrahi, M. The Sharing Economy and Digital Platforms: A Review and Research Agenda. Int. J. Inf. Manag. 2018, 43, 328-341. [CrossRef]

2. Ganapati, S.; Reddick, C.G. Prospects and challenges of sharing economy for the public sector. Gov. Inf. Q. 2018, 35, 77-87. [CrossRef]

3. Jin, S.; Kong, H.; Wu, R.; Sui, D. Ridesourcing, the Sharing Economy, and the Future of Cities. Cities 2018, 76, 96-104. [CrossRef]

4. Martín, J.M.; Martínez, J.M.; Fernández, J.A. An analysis of the factors behind the citizen's attitude of rejection towards tourism in a context of over-tourism and economic dependence on this activity. Sustainability 2018, 10, 2851. [CrossRef]

5. Martín, J.M.; Martín, J.A.; Mejía, K.A.; Fernández, J.A. Effects of vacation rental websites on the concentration of tourists-Potential environmental impacts. An application to the Balearic Islands in Spain. Int. J. Envron. Res. Public Health. 2018, 15, 347. [CrossRef] [PubMed]

6. Wu, J.; Ma, P.; Xie, K. In Sharing Economy We Trust: The Effects of Host Attributes on Short-Term Rental Purchases. Int. J. Contemp. Hosp. M. 2017, 29, 2962-2976. [CrossRef]

7. Hu, L.Q.; Liu, H.; Zou, X. An Evaluation of the User Experience on C2C Online Short-Term Rentals. Iop Conf. Ser. Earth Env. Sci. 2018, 199, 032001.

8. Andrey, F.; Elena, G.; David, H. The Determinants of Online Review Informativeness: Evidence from Field Experiments on Airbnb. SSRN Electron. J. 2018. Available online: https://ssrn.com/abstract=2939064 (accessed on 1 July 2019).

9. Zervas, G.; Proserpio, D.; Byers, J. The Rise of the Sharing Economy: Estimating the Impact of Airbnb on the Hotel Industry. SSRN Electron. J. 2013. Available online: https://ssrn.com/abstract=2366898 (accessed on 1 July 2019).

10. Yang, Y.; Mao, E.Z. Welcome to My Home! An Empirical Analysis of Airbnb Supply in US Cities. J. Travel Res. 2018, 53. [CrossRef]

11. Felson, M.; Spaeth, J.L. Community Structure and Collaborative Consumption: A Routine Activity Approach. Am. Behav. Sci. 1978, 21, 614-624. [CrossRef]

12. Botsman, R.; Rogers, R. What's Mine Is Yours: The Rise of Collaborative Consumption; Harper Business: New York, NY, USA, 2010; pp. 30-59.

13. Liu, S.Q.; Mattila, A.S. Airbnb: Online targeted advertising, sense of power, and consumer decisions. Int. J. Hosp. Manag. 2017, 60, 33-41. [CrossRef]

14. Ert, E.; Fleischer, A.; Magen, N. Trust and reputation in the sharing economy: The role of personal photos in Airbnb. Tour. Manag. 2016, 55, 62-73. [CrossRef]

15. Zhang, S.; Lee, D.; Singh, P.V.; Srinivasan, K. How Much Is an Image Worth? Airbnb Property Demand Estimation Leveraging Large Scale Image Analytics. SSRN Electron. J. 2017. Available online: https: //www.ssrn.com/abstract=2976021 (accessed on 1 July 2019). 
16. Ye, Q.; Law, R.; Gu, B.; Chen, W. The influence of user-generated content on traveler behavior: An empirical investigation on the effects of e-word-of-mouth to hotel online bookings. Comput. Hum. Behav. 2011, 27, 634-639. [CrossRef]

17. Phillips, P.; Zigan, K.; Silva, M. The interactive effects of online reviews on the determinants of Swiss hotel performance: A neural network analysis. Tour. Manag. 2015, 50, 130-141. [CrossRef]

18. Zhao, R.X.; Wang, L.; Guo, X.; Law, C.H.R. The influence of online reviews to online hotel booking intentions. Int. J. Contemp. Hosp. Manag. 2015, 27, 1343-1364. [CrossRef]

19. Ladhari, R.; Michaud, M. eWOM effects on hotel booking intentions, attitudes, trust, and website perceptions. Int. J. Contemp. Hosp. Manag. 2015, 46, 36-45. [CrossRef]

20. Tsao, W.C.; Hsieh, M.T.; Shih, L.W.; Lin, T.M. Compliance with eWOM: The influence of hotel reviews on booking intention from the perspective of consumer conformity. Int. J. Hosp. Manag. 2015, 46, 99-111. [CrossRef]

21. Porter, M. Competitive Advantage; The Free Press: New York, NY, USA, 1985.

22. Wang, H.W.; Wang, H.; Chang, H.H. The moderating effect of customer perceived value on online shopping behaviour. Online Inf. Rev. 2011, 35, 333-359.

23. Peng, L.; Zhang, W.; Wang, X.; Liang, S. Moderating effects of time pressure on the relationship between perceived value and purchase intention in social E-commerce sales promotion: Considering the impact of product involvement. Inf. Manag. 2019, 56, 317-328. [CrossRef]

24. Zeithaml, V.A. Consumer Perceptions of Price, Quality, and Value: A Means-End Model and Synthesis of Evidence. J. Mark. 1988, 52, 2. [CrossRef]

25. Darden, W.R.; Griffin, M.; Babin, B.J. Work and/or Fun: Measuring Hedonic and Utilitarian Shopping Value. J. Consum. Res. 1994, 20, 644.

26. Sweeney, J.C.; Soutar, G.N. Consumer perceived value: The development of a multiple item scale. J. Retail. 2001, 77, 203-220. [CrossRef]

27. Petrick, J.F. Development of a Multi-Dimensional Scale for Measuring the Perceived Value of a Service. J. Leis. Res. 2002, 34, 119-134. [CrossRef]

28. Bauer, R. Consumer Behavior as Risk Taking. In Proceedings of the 43rd Conference of the American Marketing Association, Chicago, IL, USA, 15-17 June 1960; pp. 389-398.

29. Cox, D.; Rich, S. Perceived Risk in Consumer Decision Making-The Case of Telephone Shopping. J. Mark. Res. 1964, 1, 32-39.

30. Peter, J.P.; Ryan, M.J. An Investigation of Perceived Risk at the Brand Level. J. Mark. Res. 1976, 13, 184. [CrossRef]

31. Jacoby, J.; Kaplan, L.; Szybillo, G. Components of Perceived Risk in Product Purchase: A Cross-Validation. J. Appl. Psychol. 1974, 59, 287-291.

32. Peter, J.P.; Tarpey, L.X. A Comparative Analysis of Three Consumer Decision Strategies. J. Consum. Res. 1975, 2, 29-37. [CrossRef]

33. Jarvenpaa, S.L.; Todd, P.A. Consumer Reactions to Electronic Shopping on the World Wide Web. Int. J. Electron. Commer. 1996, 1, 59-88. [CrossRef]

34. Jordan, E.; Moore, J. An In-Depth Exploration of Residents' Perceived Impacts of Transient Vacation Rentals. J. Travel Tour. Mark. 2018, 35, 90-101. [CrossRef]

35. Akar, E.; Dalgic, T. Understanding online consumers' purchase intentions: A contribution from social network theory. Behav. Inf. Technol. 2018, 37, 473-487. [CrossRef]

36. Nicosica, F. Consumer Decision Process-Marketing and Advertising Implications; Prentice-Hall: Englewood Cliffs, NJ, USA, 1966.

37. Mowen, J. Consumer Behaviour; Macmillan Coll Div: New York, NY, USA, 1990.

38. Feeny, P. Seasonal Changes in Oak Leaf Tannins and Nutrients as a Cause of Spring Feeding by Winter Moth Cater. Ecology 1970, 51, 565-581. [CrossRef]

39. Engel, P. Facilitating Innovation: An Action-Oriented Approach and Participatory Methodology to Improve Innovative Social Practice in Agriculture. Ph.D. Thesis, Wageningen University, Wageningen, The Netherland, 1995.

40. Chen, A.; Lu, Y.; Wang, B. Customers' purchase decision-making process in social commerce: A social learning perspective. Int. J. Inf. Manag. 2017, 37, 627-638. [CrossRef] 
41. Olbrich, R.; Holsing, C. Modeling Consumer Purchasing Behavior in Social Shopping Communities with Clickstream Data. Int. J. Electron. Commer. 2011, 16, 15-40. [CrossRef]

42. Moody, G.D.; Galletta, D.F.; Lowry, P.B. When trust and distrust collide online: The engenderment and role of consumer ambivalence in online consumer behavior. Electron. Commer. Res. Appl. 2014, 13, $266-282$. [CrossRef]

43. Godes, D.; Mayzlin, D. Using Online Conversations to Study Word-of-Mouth Communication. Mark. Sci. 2004, 23, 545-560. [CrossRef]

44. Xu, X.; Wang, X.; Li, Y.; Haghighi, M. Business Intelligence in Online Customer Textual Reviews: Understanding Consumer Perceptions and Influential Factors. Int. J. Inf. Manag. 2007, 37, 673-683. [CrossRef]

45. Mehrabian, A.; Russell, J. An Approach to Environmental Psychology; MIT Press: Cambridge, MA, USA, 1974.

46. Eroglu, S.A.; Machleit, K.A.; Davis, L.M. Empirical testing of a model of online store atmospherics and shopper responses. Psychol. Mark. 2003, 20, 139-150. [CrossRef]

47. Vermeulen, I.E.; Seegers, D. Tried and tested: The impact of online hotel reviews on consumer consideration. Tour. Manag. 2009, 30, 123-127. [CrossRef]

48. Sotiriadis, M.; Zyl, C. Electronic Word-of-Mouth and Online Reviews in Tourism Services: The Use of Twitter by Tourists. J. Electron. Commer. Re. 2017, 13, 103-124. [CrossRef]

49. Murray, K.B.; Schlacter, J.L. The impact of services versus goods on consumers' assessment of perceived risk and variability. J. Acad. Mark. Sci. 1990, 18, 51-65. [CrossRef]

50. Mhembere, D.; Roncal, W.R.; Sussman, D.L.; Priebe, C.E.; Jung, R.E.; Ryman, S.; Vogelstein, R.J.; Vogelstein, J.T.; Burns, R.C. Computing scalable multivariate global invariants of large (brain-) graphs. In Proceedings of the Global Conference on Signal \& Information Processing, Austin, TX, USA, 3-5 December 2013.

51. Featherman, M.S.; Miyazaki, A.D.; Sprott, D.E. Reducing online privacy risk to facilitate e-service adoption: The influence of perceived ease of use and corporate credibility. J. Serv. Mark. 2010, 24, 219-229. [CrossRef]

52. Cacioppo, J.; Petty, R. The Need for Cognition. J. Pers. Soc. Psychol. 1982, 42, 116-131. [CrossRef]

53. Ariff, M.S.M.; Sylvester, M.; Zakuan, N.; Ismail, K.; Ali, K.M. Consumer Perceived Risk, Attitude and Online Shopping Behaviour; Empirical Evidence from Malaysia. Iop Conf. Ser. Mater. Sci. Eng. 2014, 58, 012007. [CrossRef]

54. Chatterjee, P. Online Reviews: Do Consumers Use Them? Adv. Consum. Res. 2001, 28.

55. Poon, W.C.; Poon, W. Users' adoption of e-banking services: The Malaysian perspective. J. Bus. Ind. Mark. 2007, 23, 59-69. [CrossRef]

56. Miley, P. Perceived Risk for Shopping via the Internet among United States Consumers. Ph.D. Thesis, Texas Woman's University, Denton, TX, USA, 2001.

57. Duman, T.; Mattila, A.S. The role of affective factors on perceived cruise vacation value. Tour. Manag. 2005, 26, 311-323. [CrossRef]

58. Fishbein, M.; Ajzen, I. Belief, Attitude, Intention, and Behavior: An Introduction to Theory and Research; Addison-Wesley: Reading, MA, USA, 1975.

59. Bansal, H.S.; Voyer, P.A. Word-of-Mouth Processes within a Services Purchase Decision Context. J. Serv. Res. 2000, 3, 166-177. [CrossRef]

60. Baumgartner, H.; Homburg, C. Applications of structural equation modeling in marketing and consumer research: A review. Int. J. Res. Mark. 1996, 13, 139-161. [CrossRef]

61. Hayes, A.; Scharkow, M. The Relative Trustworthiness of Inferential Tests of the Indirect Effect in Statistical Mediation Analysis: Does Method Really Matter? Psychol. Sci. 2013, 24, 1918-1927. [CrossRef]

62. Zhao, J.; Fang, S.; Jin, P. Modeling and Quantifying User Acceptance of Personalized Business Modes Based on TAM, Trust and Attitude. Sustainability 2018, 10, 356. [CrossRef]

63. Zhao, J.; Wang, J.; Fang, S.; Jin, P. Towards Sustainable Development of Online Communities in the Big Data Era: A Study of the Causes and Possible Consequence of Voting on User Reviews. Sustainability 2018, 10, 3156. [CrossRef]

(C) 2019 by the authors. Licensee MDPI, Basel, Switzerland. This article is an open access article distributed under the terms and conditions of the Creative Commons Attribution (CC BY) license (http://creativecommons.org/licenses/by/4.0/). 